\title{
Perbedaan Status Perkembangan dan Pertumbuhan Anak dengan Penyakit Jantung Bawaan Sianotik dan Non-sianotik
}

\author{
Janaka Pambudi, Meita Dhamayanti, Rahmat Budi Kuswiyanto \\ Departemen Ilmu Kesehatan Anak Fakultas Kedokteran Universitas Padjadjaran Rumah Sakit Dr. Hasan Sadikin, Bandung
}

\begin{abstract}
Latar belakang. Penyakit jantung bawaan (PJB) merupakan faktor risiko terjadinya gangguan tumbuh kembang pada anak. Anak dengan PJB sianotik dan non-sianotik memiliki karakteristik klinis yang berbeda sehingga perkembangan dan pertumbuhannya juga berbeda.

Tujuan. Mengetahui perbedaan perkembangan dan pertumbuhan anak dengan PJB sianotik dan non-sianotik.

Metode. Penelitian berupa observasional potong lintang dengan subjek penelitian adalah anak dengan PJB usia 1-3 tahun yang datang ke pelayanan rawat jalan RSUP Dr. Hasan Sadikin pada bulan Agustus sampai Oktober 2018. Penilaian perkembangan menggunakan Ages and Stages Questionnaires-3 (ASQ-3) dan penilaian pertumbuhan dengan WHO growth chart standarts 2006. Analisis data dilakukan dengan uji hipotesis Chi-square.

Hasil. Terdapat 86 subjek penelitian terdiri dari 46 perempuan dan 40 laki-laki, dengan 31 subjek merupakan PJB sianotik. Gangguan perkembangan motorik lebih banyak pada anak dengan penyakit jantung bawaan siaonotik $(\mathrm{p}<0,05)$. Gangguan perkembangan motroik kasar pada PJB non-sianotik dan sianotik yaitu 87,1\% dan 43.6\%, motorik halus yaitu 64,5\% dan 38,2\%. Tidak terdapat perbedaan yang signifikan pada pertumbuhan antara PJB sianotik dan non-sianotik.

Kesimpulan. Gangguan perkembangan motorik kasar dan halus lebih banyak terjadi pada anak dengan PJB sianotik. Tidak terdapat perbedaan gangguan pertumbuhan pada anak dengan PJB sianotik dan non-sianotik. Sari Pediatri 2019;21(2):102-8
\end{abstract}

Kata kunci: anak, penyakit jantung bawaan, tumbuh kembang

\section{Growth and Development in Children with Cyanotic and Acyanotic Congenital Heart Disease}

Janaka Pambudi, Meita Dhamayanti, Rahmat Budi Kuswiyanto

Background. Congenital heart disease (CHD) in children is a risk factor in growth and development disorder. Children with cyanotic and non-cyanotic CHD have different clinical manifestations therefore their growth and development are also different.

Objective. To evaluate the difference between growth and development in dildren with cyanotic and acyanotic congenital heart disease. Methods. During August until October 2018, observational analytic study with cross-sectional design was conducted 1 to 3 years old children who came to cardiology outpatient clinic at Hasan Sadikin General Hospital, we used Ages and stage questionnaires-3 (ASQ-3) to assess their development and WHO growth chart standards 2006 to assess their growth. Chi-square hypothesis test is used to analyze data.

Result. There were 86 subjects consist of 46 girls and 40 boys, 31 subjects were cyanotic CHD. There was significant difference in developmental disorder between cyanotic and non-cyanotic CHD in motor aspect $(\mathrm{p}<0,05)$. Gross motor delay in cyanotic and noncyanotic CHD are 87,1 and 43,6\%, while in fine motor delay are 64,5 and 38,2\%.

Conclusion. No significant difference in growth between cyanotic and non-cyanotic CHD. Gross and fine motor delay occurs most often in children with cyanotic CHD. No significant difference in growth between cyanotic and non-cyanotic CHD. Sari Pediatri 2019;21(2):102-8

Keywords: children, congenital heart disease, growth, development

Alamat korespondensi: Meita Dhamayanti. Departemen. Ilmu Kesehatan Anak, Fakultas Kedokteran Univesitas Padjadjaran, Rumah Sakit Dr. Hasan Sadikin Bandung, Jln Pasteur no 38 Bandung., Email: meita.dh@gmail.com 
Janaka Pambudi dkk: Perbedaan status perkembangan dan pertumbuhan anak dengan PJB sianotik dan non-sianotik

$\mathrm{P}$ enyakit jantung bawaan (PJB) merupakan kelainan kongenital yang paling sering terjadi pada anak. Prevalensi total kelahiran penyakit jantung bawaan antara 6,9 hingga 9,3 per 1000 kelahiran hidup. ${ }^{1}$ Penyakit jantung bawaan dapat diklasifikasikan menjadi dua kelompok, yakni PJB non-sianotik dan sianotik. Masalah yang sering menyertai anak dengan PJB salah satunya adalah gangguan perkembangan dan malnutrisi, ${ }^{2}$ keadaan ini berhubungan dengan hipoksia, ${ }^{3}$ hipermetabolisme, asupan nutrisi yang kurang dan malabsorbsi usus yang terjadi pada anak dengan PJB. ${ }^{4}$ Anak dengan PJB memiliki keterbatasan fisik untuk melakukan aktivitasnya. Gangguan kemampuan fisik juga menghambat perkembangan keterampilan motorik. ${ }^{5}$

Gangguan perkembangan pada anak dengan PJBdapat dideteksi dengan menggunakan Ages and Stages Questionnaires-3 (ASQ-3) yang memiliki spesifisitas dan sensitivitas yang tinggi (90 dan 80\%). ${ }^{6}$ Ages and Stages Questionnaires mudah digunakan sehingga kecurigaan terjadinya gangguan perkembangan dapat diketahui lebih awal dan diintervensi lebih cepat pada pasien anak dengan PJB. ${ }^{6}$ Bila dibandingkan dengan alat skrining lain yang menggunakan informasi dari orang tua, seperti Denver II, Child Development Review Parent Questionnaires (CDR-PQ) dan Parents Evaluation of Development Status (PEDS), ASQ-3 membutuhkan waktu yang singkat dalam pengerjaan dibandingkan yang lain. ${ }^{7}$ Ages and Stages Questionnaires juga telah digunakan sebagai alat skrining perkembangan oleh The American Academy of Pediatrics (AAP) sejak tahun $2006,{ }^{8}$ tetapi belum di rekomendasikan untuk pasien anak dengan PJB. ${ }^{9}$ Penilaian status gizi pada anak dapat menggunakan WHO growth chart standarts 2006 (z-score) ${ }^{10}$

Penelitian ini bertujuan mengetahui perbedaan perkembangan dan pertumbuhan pada anak dengan PJB sianotik dan non-sianotik di Bagian Ilmu Kesehatan Anak RSUP Dr. Hasan Sadikin Bandung.

\section{Metode}

Penelitian observasional dengan menggunakan rancangan potong lintang. Subjek penelitian adalah anak dengan PJB yang datang ke instalasi pelayanan rawat jalan RSUP Dr. Hasan Sadikin pada bulan Agustus sampai dengan Oktober 2018, yang dipilih secara consecutive sampling. Penentuan besar sampel penelitian berdasarkan rumus ukuran sampel untuk menguji perbedaan dua rata-rata. Subjek minimal yang diperlukan didapatkan 84 subjek. Kriteria inklusi adalah pasien anak dengan PJB sianotik dan non-sianotik yang sudah terdiagnosis sebelumnya melalui anamnesis, pemeriksaan fisis foto toraks, elektrokardiogram dan ekokardiografi, usia antara 1-36 bulan, dan belum dilakukan skrining perkembangan. Kriteria eksklusi adalah anak yang telah terdiagnosis penyakit kronik (keganasan, tuberkulosis, sindrom nefrotik dan sirosis hepatis), kelainan genetik, sindroma Down, riwayat kern ikterus, riwayat kejang, riwayat asfiksia, lahir prematur, dan sindrom rubela kongenital.

Penelitian ini dilakukan di instalasi pelayanan rawat jalan RSUP Dr. Hasan Sadikin Bandung selama Agustus - Oktober 2018 setelah mendapat persetujuan dari Komite Etik Penelitian RSUP Dr. Hasan Sadikin Bandung. Orangtua subjek penelitian bersedia anaknya diikutsertakan dalam penelitian dengan menandatangani surat persetujuan. Subjek penelitian dilakukan penilaian perkembangan dengan menggunakan ASQ-3 melalui wawancara dengan orang tua. Ages and Stages Questionnaires yang telah diterjemahkan dan divalidasi dalam bahasa Indonesia merupakan alat skrining perkembangan anak berupa pertanyaan terhadap orang tua dan observasi tingkah laku anak, pada pelaksanaanya tidak dilakukan intervensi langsung pada anak. Setiap aspek perkembangan terdiri 6 pertanyaan, yang dapat dijawab dengan "ya", "kadang-kadang", atau "belum". Setiap jawaban tersebut memiliki poin yang nantinya akan di jumlahkan menjadi total poin setiap aspek. Total poin tersebut menentukan interpretasi perkembangan (normal atau gangguan perkembangan) berdasarkan nilai cut-off sesuai usia disetiap domain perkembangan. ${ }^{11}$ Interpretasi normal apabila total poin lebih tinggi dari cut-off, sedangkan interpretasi gangguan perkembangan apabila total poin lebih rendah dari cut-off. ${ }^{11}$ Pemeriksaan antropometri menggunakan kurva WHO growth chart standarts 2006, dengan berat badan dibanding usia $<-2$ Standar deviasi (SD) dikategorikan sebagai underweight, panjang badan dibanding usia <-2 SD dikategorikan sebagai stunted, berat badan dibandingkan panjang badan $<-2$ SD dikategorikan sebagai wasted dan $>1$ SD dikategorikan sebagai risk of overweight. ${ }^{10}$ Klasifikasi penghasilan keluarga dan pendidikan orang tua diambil berdasarkan data yang dikeluarkan Badan Pusat Statistik (BPS) Indonesia. ${ }^{12}$ 
Data yang diperoleh kemudian dimasukkan ke dalam program perangkat lunak SPSS ${ }^{\odot}$ for windows versi 24. Variabel bebas pada penelitian ini adalah anak dengan PJB sianotik dan non-sianotik sedangkan variabel terikat adalah penilaian perkembangan dan pertumbuhan. Analisis data menggunakan chi-square untuk membandingkan data kategorik dan menggunakan uji Mann-Whitney pada data berdistribusi tidak normal. Kemaknaan hasil uji ditentukan berdasarkan nilai $\mathrm{p}<0,05$.

\section{Hasil}

Penelitian telah dilakukan pada 86 pasien PJB yang datang ke instalasi pelayanan rawat jalan RSUP. Hasan Sadikin Bandung. Terhadap semua subjek data dilakukan pencatatan data karakteristik yaitu jenis kelamin, usia, berat lahir, usia kehamilan, diagnosis PJB, pendidikan dan pekerjaan ayah dan ibu, penghasilan perbulan kedua orang tua. Hasil penelitian selengkapnya tertera pada Tabel 1 berikut ini.

Tabel 1. Karakteristik subjek penelitian

\begin{tabular}{|c|c|c|c|}
\hline \multirow[b]{2}{*}{ Karakteristik } & \multicolumn{2}{|c|}{ Kelompok } & \multirow[b]{2}{*}{ Total n (\%) } \\
\hline & $\begin{array}{c}\text { Sianotik }(\mathrm{n}=31) \\
\mathrm{n}(\%)\end{array}$ & $\begin{array}{c}\text { Non-sianotik }(\mathrm{n}=55) \\
\mathrm{n}(\%)\end{array}$ & \\
\hline \multicolumn{4}{|l|}{ Jenis kelamin } \\
\hline Laki-laki & $14(35)$ & $26(65)$ & $40(46,5)$ \\
\hline Perempuan & $17(37)$ & $29(63)$ & $46(53,5)$ \\
\hline \multicolumn{4}{|l|}{ Usia (bulan) } \\
\hline Rata-rata (SD) & $18,3(7,7)$ & $16,2(9,0)$ & \\
\hline \multicolumn{4}{|l|}{ Berat lahir (gram) } \\
\hline Rata-rata (SD) & $2788,7(422,4)$ & $2660,6(507,4)$ & \\
\hline \multicolumn{4}{|l|}{ Usia kehamilan } \\
\hline Cukup bulan & $29(42)$ & $40(58)$ & $69(80,2)$ \\
\hline Kurang bulan & $2(11,8)$ & $15(88,2)$ & $17(19,8)$ \\
\hline \multicolumn{4}{|l|}{ Pendidikan ayah } \\
\hline SD & $6(35,3)$ & $11(64,7)$ & $17(19,8)$ \\
\hline SMP & $10(41,7)$ & $14(58,3)$ & $24(27,9)$ \\
\hline SMA/SMK & $11(37,9)$ & $18(62,1)$ & $29(33,7)$ \\
\hline $\mathrm{Ak} / \mathrm{PT}$ & $4(25)$ & $12(75)$ & $16(18,6)$ \\
\hline \multicolumn{4}{|l|}{ Pekerjaan ayah } \\
\hline Buruh & $15(34,9)$ & $28(65,1)$ & $43(50)$ \\
\hline Pegawai swasta & $13(36,1)$ & $23(63,9)$ & $36(41,9)$ \\
\hline PNS/ABRI & $3(42,9)$ & $4(57,1)$ & $7(8,1)$ \\
\hline \multicolumn{4}{|l|}{ Pendidikan ibu } \\
\hline SD & $5(45,5)$ & $6(54,5)$ & $11(12,8)$ \\
\hline SMP & $11(35,5)$ & $20(64,5)$ & $31(36)$ \\
\hline SMA/SMK & $10(43,5)$ & $13(56,5)$ & $23(26,7)$ \\
\hline $\mathrm{Ak} / \mathrm{PT}$ & $5(23,8)$ & $16(76,2)$ & $21(34,4)$ \\
\hline \multicolumn{4}{|l|}{ Pekerjaan ibu } \\
\hline Bekerja & $2(28,6)$ & $5(71,4)$ & $7(8,1)$ \\
\hline Tidak bekerja & $29(36,7)$ & $50(63,3)$ & $79(91,9)$ \\
\hline \multicolumn{4}{|c|}{ Penghasilan keluarga } \\
\hline Rendah & $9(39,1)$ & $14(60,9)$ & $23(26,7)$ \\
\hline Sedang & $11(32,4)$ & $23(67,6)$ & $34(39,5)$ \\
\hline Tinggi & $9(50)$ & $9(50)$ & $18(20,9)$ \\
\hline Sangat tinggi & $2(18,2)$ & $9(81,8)$ & $11(12,8)$ \\
\hline
\end{tabular}

Keterangan: SD: sekolah dasar, SMP: sekolah menengah pertama, SMA: sekolah menengah akhir, SMK: sekolah menengah kejuruan, Ak: akademi, PT: perguruan tinggi, PNS: pegawai negeri sipil, TNI: tentara nasional Indonesia, IRT: ibu rumah tangga, PJB: penyakit jantung bawaan 
Tabel 1 menyajikan karakteristik subjek penelitian, berdasarkan hasil pemeriksaan pada anak dengan PJB diperoleh jenis sianotik 31 (36\%) dan non-sianotik 55 (64\%). Tampak komposisi penderita berdasarkan jenis kelamin tidak jauh berbeda, usia antara 2-38 bulan. Sebagian besar usia kehamilan adalah aterm, pendidikan ayah terbanyak SLTA (33,7\%), sedangkan pendidikan ibu SMP (36\%). Untuk pekerjaan ayah terbanyak adalah buruh (50\%), sedangkan sebagian besar ibu adalah tidak bekerja/ibu rumah tangga $(91,9 \%)$.

Pada Tabel 2 tertera distribusi frekuensi berdasarkan klasifikasi jenis PJB. Pasien dengan PJB nonsianotik terdapat 55 pasien (64\%) dan pasien dengan PJB sianotik ialah 31 pasien (36\%). Penyakit jantung bawaan sianotik terbanyak adalah tetralogy of falot

Tabel 2. Distribusi frekuensi berdasarkan Jenis PJB

\begin{tabular}{lcc}
\hline Jenis PJB & $\mathrm{n}$ & $(\%)$ \\
\hline Sianosis & 16 & \\
TOF & 2 & 18,6 \\
TGA & 6 & 2,3 \\
Pulmonal atresia & 2 & 6,9 \\
Trikuspid atresia & 1 & 2,3 \\
Trikuspid atresia + Pulmonal atresia & 1 & 1,1 \\
VSD + Pulmonal stenosis & 1 & 1,1 \\
DORV + VSD + pulmonal stenosis & 2 & 1,1 \\
Ebstein anomaly & & 2,3 \\
\hline Non-sianotik & 1 & \\
ASD & 25 & 1,1 \\
VSD & 21 & 29 \\
PDA & 2 & 24,4 \\
ASD + VSD & 3 & 2,3 \\
PDA + VSD & 2 & 3,4 \\
ASD + Pulmonal stenosis & 1 & 2,3 \\
Pulmonal stenosis & 1,1 \\
\hline
\end{tabular}

Keterangan: VSD: Ventricular septal defect, ASD: Atrial septal defect, PDA: Patent ductus arteriosus, TOF: Tetralogy of Fallot, TGA: Transposition of the great arteries

Tabel 3. Perbedaan status antropometri antara anak dengan penyakit jantung sianotik dan non-sianotik

\begin{tabular}{|c|c|c|c|}
\hline \multirow[b]{2}{*}{ Variabel } & \multicolumn{2}{|l|}{ Kelompok } & \multirow[b]{2}{*}{ Nilai $p$} \\
\hline & $\begin{array}{l}\text { Sianotik } \\
\mathrm{n}(\%)\end{array}$ & $\begin{array}{l}\text { Non-sianotik } \\
\mathrm{n}(\%)\end{array}$ & \\
\hline BB/usia & & & 0,225 \\
\hline Normal & $19(41,3)$ & $27(58,7)$ & \\
\hline Underweight & $11(35,5)$ & $20(64,5)$ & \\
\hline Severely underweight & $1(11,1)$ & $8(88,9)$ & \\
\hline $\mathrm{PB} /$ usia & & & 0,680 \\
\hline Normal & $13(32,5)$ & $27(67,5)$ & \\
\hline Stunted & $10(35,7)$ & $18(64,3)$ & \\
\hline Severely stunted & $8(44,4)$ & $10(55,6)$ & \\
\hline $\mathrm{BB} / \mathrm{PB}$ & & & 0,197 \\
\hline Normal & $22(38,6)$ & $35(61,4)$ & \\
\hline Wasted & $6(30)$ & $14(70)$ & \\
\hline Severely wasted & $1(33,3)$ & $2(66,7)$ & \\
\hline Possible risk overweight & $2(33,3)$ & $4(66,7)$ & \\
\hline
\end{tabular}

Keterangan: BB: berat badan, PB: panjang badan 
Janaka Pambudi dkk: Perbedaan status perkembangan dan pertumbuhan anak dengan PJB sianotik dan non-sianotik

Tabel 4. Perbedaan status perkembangan antara anak dengan penyakit jantung sianotik dan non sianotik

\begin{tabular}{lccc}
\hline & \multicolumn{2}{c}{ Kelompok } & \\
\cline { 2 - 3 } Domain perkembangan & $\begin{array}{c}\text { Sianotik } \\
\mathrm{n}(\%)\end{array}$ & $\begin{array}{c}\text { Non-sianotik } \\
\mathrm{n}(\%)\end{array}$ & Nilai p \\
\hline Komunikasi & $31(100)$ & $52(94,5)$ & 0,550 \\
$\quad$ Normal & $0(0)$ & $3(5,5)$ & \\
$\quad$ Suspek gangguan perkembangan & & & $<0,001$ \\
Motorik kasar & $4(12,9)$ & $31(56,4)$ & \\
$\quad$ Normal & $27(87,1)$ & $24(43,6)$ & \\
$\quad$ Suspek gangguan perkembangan & $11(35,5)$ & $34(61,8)$ & \\
Motorik halus & $20(64,5)$ & $21(38,2)$ & \\
$\quad$ Normal & & & 0,019 \\
$\quad$ Suspek gangguan perkembangan & $25(80,6)$ & $44(80)$ & \\
Pemecahan masalah & $6(19,4)$ & $11(20)$ & \\
$\quad$ Normal & & & 0,726 \\
$\quad$ Suspek gangguan perkembangan & $25(80,6)$ & $46(83,6)$ & \\
Personal sosial & $6(19,4)$ & $9(16,4)$ & \\
$\quad$ Normal & & & \\
$\quad$ Suspek gangguan perkembangan & & & \\
\hline
\end{tabular}

(18,6\%). Pada kelompok PJB non-sianotik yang terbanyak adalah Ventricular septal defect (29\%) dan Patent ductus arteriosus (24,4\%).

Pengukuran gangguan perkembangan yang terdiri dari lima domain, yaitu gangguan komunikasi, motorik kasar, motorik halus, pemecahan masalah dan personal sosial. Gangguan perkembangan yang menunjukkan ada perbedaan bermakna pada kedua kelompok PJB adalah motorik kasar dan motorik halus. Gangguan perkembangan motorik kasar dan motorik halus pada penderita PJB sianotik lebih banyak bila dibandingkan dengan PJB non sianotik. Selanjutnya, dari lima jenis gangguan perkembangan dengan menetapkan salah satu mengalami gangguan perkembangan kedalam gangguan perkembangan, diperoleh 63 kasus PJB $(73,3 \%)$ mengalami gangguan perkembangan.

\section{Pembahasan}

Hasil perkembangan motorik kasar dan motorik halus yang normal, lebih banyak ditemukan pada anak dengan PJB non-sianotik dibandingkan dengan PJB sianotik. Domain perkembangan motorik kasar dan halus pada anak dengan PJB paling sering mengalami gangguan dibandingkan domain perkembangan yang lain. ' Gangguan perkembangan yang berat pada fungsi motorik dapat berpengaruh pada fungsi psikososial seorang anak di kemudian hari. ${ }^{9,13}$ Pada penelitian Holm $\mathrm{dkk},{ }^{14}$ anak dengan PJB secara bermakna mengalami penurunan kekuatan otot dan gangguan keseimbangan. Kekuatan otot dan keseimbangan merupakan komponen penting dari perkembangan motorik karena dalam beberapa tingkat tertentu keduanya diperlukan untuk melakukan fungsi-fungsi tertentu.

Pada penelitian ini didapatkan perkembangan bahasa yang normal, baik pada anak dengan PJB sianotik maupun PJB non-sianotik, dan tidak ditemukan perbedaan yang bermakna di antara kedua grup. Terdapat perbedaan hasil penelitian yang dilakukan oleh Brandlistuen dkk. ${ }^{15}$ Penelitian tersebut mendapatkan anak dengan PJB berat dan PJB disertai komorbid secara bermakna mengalami gangguan pada perkembangan bahas dan psikososial. Menurut Bellinger, ${ }^{16}$ kemampuan berbahasa merupakan indikator seluruh perkembangan anak karena kemampuan berbahasa sensitif terhadap keterlambatan pada sistem lainnya, sebab melibatkan kemampuan kognitif, motorik dan psiko-sosial.

Pada kasus PJB non-sianotik ditemukan gambaran pertumbuhan secara keseluruhan berstatus gizi baik. Hasil yang sama didapatkan juga pada kelompok PJB sianotik, ditemukan mayoritas berstatus gizi baik. Biasanya, pasien dengan PJB sianotik mengalami gangguan pertumbuhan yang lebih berat dari pasien PJB non-sianotik. Pasien dengan PJB sianotik 
biasanya menunjukkan berat badan dan tinggi badan yang kurang dari anak seusianya., ${ }^{2}$ Sesuai dengan penelitian sebelumnya, gangguan pertumbuhan pada anak dengan PJB banyak terjadi pada usia $>5$ tahun, sedangkan usia 1-4 tahun mayoritas petumbuhan normal. ${ }^{18} \mathrm{Hal}$ ini mungkin disebabkan karena asupan nutrisi anak dapat lebih mudah dioptimalkan sehingga tidak sampai mengganggu pertumbuhannya. ${ }^{19,20}$

Gambaran pertumbuhan pasien yang didapatkan berdasarkan penilaian berat badan menurut usia terbanyak pada status gizi normal, yaitu 27 dan 19 pasien pada grup non-sianotik dan sianotik $(58,7 \%$ dan $41,3 \%)$. Pada penilaian tinggi badan menurut usia, jumlah pasien terbanyak juga pada status gizi normal 27 dan 13 pasien pada grup non-sianotik dan sianotik $(67,5 \%$ dan 32,5\%). Berdasarkan penilaian berat badan menurut tinggi badan, ditemukan gambaran pertumbuhan terbanyak pada status gizi normal sebanyak 35 dan 22 pasien pada grup nonsianotik dan sianotik (61,4\% dan 38,6\%). Hasil ini berbeda dengan penelitian sebelumnya oleh Maramis $\mathrm{dkk}^{18}$ yang melaporkan bahwa anak dengan status gizi kurang adalah yang paling banyak. Pada penelitian oleh Rahayuningsih, ${ }^{21}$ malnutrisi hanya terlihat jelas pada anak PJB dengan komorbiditas.

Keterbatasan penelitian ini adalah tidak dimasukkannya data pola asuh orang tua pada anak dengan PJB. Perkembangan seorang anak akan sangat berkaitan dengan pola asuh orang tua saat di rumah. Data mengenai jumlah anak dalam suatu keluarga juga dapat berpengaruh pada kualitas seorang anak mendapatkan stimulasi dari orang tua yang berguna bagi tumbuh kembang yang optimal. Usia kehamilan kurang bulan dan berat badan lahir yang kurang pada penelitian tidak dimasukan sebagai faktor perancu pada penelitian ini. Kondisi orang tua dengan status single parent tidak dimasukkan pada data penelitian, yang mungkin berhubungan dengan cukup tidaknya pemberian stimulasi oleh orang tua. Derajat hipoksia pada kelompok sianotik perlu dimasukkan dalam hasil penelitian sebagai faktor perancu penelitian.

\section{Kesimpulan}

Berdasarkan hasil penelitian, dugaan gangguan perkembangan motorik kasar dan halus lebih banyak terjadi pada anak dengan PJB sianotik. Tidak terdapat perbedaan gangguan pertumbuhan pada anak dengan
PJB sianotik dan non-sianotik. Skrining perkembangan dan pemeriksaan status pertumbuhan perlu dilakukan secara teratur pada anak dengan penyakit jantung.

\section{Daftar pustaka}

1. van der Linde D, E M Konings E, A Slager M, Witsenburg M, Helbing W, Takkenberg J, dkk. Birth prevalence of congenital heart disease worldwide. J Am Coll Cardiol 2011;58:2241-7.

2. Nasiruzzaman AHM, Hussain MZ, Baki MA, Tayeb MA, Mollah MN. Growth and developmental status of children with congenital heart disease. Bangladesh Med J 2011;40:54-7.

3. Ghimire LV. Congenital heart disease and high altitude: is chronic hypoxia a common factor in intellectual impairment? High Alt Med Biol 2017;18:299-300.

4. Hubschman LE. Malnutrition in congenital heart disease: management to improve outcomes. ICAN: Infant, Child, \& Adolescent Nutr 2013;5:170-6.

5. Wray J, Sensky T. Controlled study of preschool development after surgery for congenital heart disease. Arch Dis Child 1999;80:511-6.

6. Noeder MM, Logan BA, Struemph KL, Condon N, Mueller I, Sands B, dkk. Developmental screening in children with CHD: Ages and Stages Questionnaires. Cardiol young 2017;27:1447-54

7. Brookes. Commonly used parent-report developmental screening tools. Paul H. Brookes Publishing Co; 2018 [cited 2018]; Didapat dari: https://agesandstages.com/wp-content/ uploads/2018/01/Comparison-Chart-2018.pdf.

8. Singh A, Yeh CJ, Boone Blanchard S. Ages and stages questionnaire: a global screening scale. Boletín Médico del Hospital Infantil de México 2017 74:5-12.

9. Marino BS, Lipkin PH, Newburger JW, Peacock G, Gerdes M, Gaynor JW, dkk. Neurodevelopmental outcomes in children with congenital heart disease: evaluation and management. Circulation 2012;126:1143-72.

10. World Health Organization. The WHO child growth standards. World Health Organization; 2006; Didapat dari: https://www.who.int/childgrowth/en/.

11. Squires J, Twombly E, Bricker DD, Potter L. Ages and stages questionnaires-3: user's guide. Baltimore: Paul H. Brookes Publishing Co; 2009.

12. Statistik BP. Laju pertumbuhan ekonomi. Badan Pusat Statistik; 2017; dIdapat dari: https://bandungkota.bps.go.id/.

13. Brandlistuen RE, Stene-Larsen K, Holmstrom H, Landolt MA, Eskedal LT, Vollrath ME. Motor and social development in 6-month-old children with congenital heart defects. J Pediatr 2010;156:265-9. 
14. Holm I, Fredriksen PM, Fosdahl MA, Olstad M, Vøllestad N. Impaired motor competence in school-aged children with complex congenital heart disease. Arch PediatrAdolesc Med 2007;161:945-50.

15. Brandlistuen RE, Stene-Larsen K, Holmstrøm H, Landolt MA, Eskedal LT, Vollrath ME. Symptoms of communication and social impairment in toddlers with congenital heart defects. Child: Care, Health and Development 2011;37:37-43.

16. Bellinger DC, Newburger JW. Late neurodevelopmental outcomes in children with congenital heart disease. Dalam: Baron IS, Rey-Casserly C, penyunting. Pediatric neuropsychology: Medical advances and lifespan outcomes. Edisi pertama. Oxford University Press; 2013.h.99-112.

17. Cafrina G, Firman A, Nugraha GI. Nutritional status of tetralogy of fallot patients at Dr. Hasan Sadikin General Hospital Bandung. AMJ 2016;3:298-303.

18. Maramis PP, Rompis J. Hubungan penyakit jantung bawaan dengan status gizi pada anak di RSUP Prof. Dr. R. D. Kandou Manado tahun 2009-2013. Jurnal e-clinic 2014;2:1-9.

19. Medoff-Cooper B, Ravishankar C. Nutrition and growth in congenital heart disease: a challenge in children. Curr Opin Cardiol 2013;28:122-9.

20. Arodiwe I, Chinawa J, Ujunwa F, Adiele D, Ukoha M, Obidike E. Nutritional status of congenital heart disease (CHD) patients: Burden and determinant of malnutrition at university of Nigeria teaching hospital Ituku - Ozalla, Enugu. Pak JMed Sci 2015;31:1140-5.

21. Rahayuningsih SE. Hubungan antara defek septum ventrikel dan status gizi. Sari Pediatri 2011;13:137-41. 